\title{
Impact of secondhand smoke exposure in former smokers on their subsequent risk of coronary heart disease: evidence from the population-based cohort of the Tehran Lipid and Glucose Study
}

\author{
Masoumeh Sadeghi', Maryam S. Daneshpour², Soheila Khodakarim', Amir Abbas Momenan³, \\ Mahdi Akbarzadeh2, Hamid Soori ${ }^{1,4}$ \\ ${ }^{1}$ Department of Epidemiology, School of Public Health and Safety, Shahid Beheshti University of Medical Sciences, Tehran, Iran; ${ }^{2}$ Cellular and \\ Molecular Endocrine Research Center, Research Institute for Endocrine Sciences, Shahid Beheshti University of Medical Sciences, Tehran, Iran; \\ ${ }^{3}$ Prevention of Metabolic Disorders Research Center, Research Institute for Endocrine Sciences, Shahid Beheshti University of Medical Sciences, \\ Tehran, Iran; ${ }^{4}$ Safety Promotion and Injury Prevention Research Center, Shahid Beheshti University of Medical Sciences, Tehran, Iran
}

\begin{abstract}
OBJECTIVES: Cigarette smoking is an established, strong, and modifiable risk factor for coronary heart disease (CHD). However, little research has investigated CHD risk in former smokers who continue to be exposed to others' cigarette smoke (former \& secondhand smokers).

METHODS: In the Tehran Lipid and Glucose Study, a prospective population-based cohort ( $n=20,069)$ was followed up for a median period of 14.6 years. A subset of 8,050 participants of 30 years of age and older was analyzed, with first CHD events as the study outcome. Participants were categorized as never, former, current, secondhand, and former \& secondhand smokers. Data on smoking intensity (cigarette/d) were also collected. A Cox proportional hazards regression model was applied to estimate the risk of $\mathrm{CHD}$, taking into account the main potential confounders.

RESULTS: The mean age of participants was $46.10 \pm 11.38$ years, and they experienced 1,118 first CHD events (with most CHD cases in former smokers) during the follow-up period. The risk of CHD was highest in current smokers, followed in order by former \& secondhand, former, and secondhand smokers (hazard ratio [HR], 1.99; 95\% confidence interval [CI], 1.65 to 2.39; HR, 1.55 ; $95 \%$ CI, 1.15 to 2.08 ; HR, 1.39; $95 \%$ CI, 1.12 to 1.72 ; HR, 1.27 ; $95 \%$ CI, 1.07 to 1.51 , respectively), compared to never smokers. The risk of $\mathrm{CHD}$ increased with smoking intensity, which has been proposed as a preferable measure of smoking, indicating a dose-response pattern.
\end{abstract}

CONCLUSIONS: The elevated risk of CHD in former \& secondhand smokers was a noteworthy finding, with possible implications for health policy; however, further research is needed.

KEY WORDS: Smoking, Coronary heart disease, Cohort studies, Tehran Lipid and Glucose Study

\section{Correspondence: Hamid Soori}

Department of Epidemiology, School of Public Health and Safety, Shahid Beheshti University of Medical Sciences, Velenjak Street, Tehran 1983969411, Iran

E-mail: hsoori@yahoo.com

Received: Feb 1, 2020 / Accepted: Mar 7, 2020 / Published: Mar 8, 2020

This article is available from: https://e-epih.org/

(c) This is an open-access article distributed under the terms of the Creative Commons Attribution License (https://creativecommons.org/licenses/by/4.0/), which permits unrestricted use, distribution, and reproduction in any medium, provided the original work is properly cited.

(C) 2020, Korean Society of Epidemiology

\section{INTRODUCTION}

Despite remarkable advances in the treatment of cardiovascular disease (CVD) — and in particular, coronary heart disease (CHD) CVD and its clinical sequelae continue to be the leading cause of morbidity and mortality worldwide [1-3]. Based on the available evidence, $\mathrm{CHD}$ is a major concern for global health, as well as a major barrier to achieving the Sustainable Development Goals $[1,4]$. CHD has been found to be the main cause of death in Iran, and it is projected that the years of life lost due to CHD will increase dramatically in the coming years $[5,6]$. 
Overall, 1.4 billion adults worldwide smoke, of whom 1.12 billion are males and 279 million are females [7]. Although the prevalence of current smokers has decreased over time in several countries, the global absolute number of smokers has increased owing to population growth [8]. Cigarette smoking is an established, strong, and modifiable risk factor for $\mathrm{CHD}$ [9-11]. In recent years, several observational studies have focused on the associations between cigarette smoking and CVD, myocardial infarction (MI), $\mathrm{CHD}$, and stroke [12-15]. Some studies have addressed smoking behavior as a simple dichotomous (smoker/non-smoker) variable, while a few prospective cohort studies have operationalized cigarette smoking in multiple ways, such as smoking status (never, former, and current smoker), pack/yr, duration, and age of onset of smoking in various age groups and communities [16,17]. Based on the Framingham cohort study findings, former heavy smokers have significantly elevated CVD risk extending beyond 5 years after cessation compared to never smokers [18]. A recently published systematic review and meta-analysis indicated that smoking only about 1 cigarette/d resulted in an additional risk of developing CHD and stroke that was much greater than expected [9].

Although our knowledge base in relation to the effect of cigarette smoking (current and former vs. never smokers) on CHD risk has expanded over the last decade, comparatively little research has been conducted on secondhand smokers and former smokers who are still exposed to others' cigarette smoke. The limitations of published data leave open important questions about the magnitude and effect size of CHD risk in individuals who are exposed to others' cigarette smoke after cigarette smoking quitting/cessation.

In an attempt to fill this evidence gap, the present study set out to explore the influence of smoking status (former, current, and secondhand smoking, and in particular secondhand exposure following smoking cessation compared to never smoking) as well as smoking intensity (as another proposed measure of cigarette smoking) on the subsequent risk of CHD.

\section{MATERIALS AND METHODS}

\section{Study design}

The Tehran Lipid and Glucose Study (TLGS) is an open-ended prospective population-based cohort study of a representative sample of residents of Tehran (the capital city of Iran) who were 3 years of age and older at the time of recruitment. This study originated in March 1999 to December 2001, and follow-up and data collection were planned to be accomplished at 3-year intervals. Briefly, 15,005 individuals participated in the first examination and 3,550 individuals were added in the second examination. Newborn children of families were added to the study population after they reached 3 years of age during the follow-up. The study population includes 20,069 individuals, and to date, the median follow-up time of this cohort is 14.66 years (interquartile range [IQR], 10.45 to 6.22 ). The details of the TLGS cohort study have been described elsewhere [19-21].

\section{Study sample}

A subset of 8,050 participants from the TLGS cohort was considered. The included individuals were restricted to those who were 30 years of age and older. Furthermore, participants who had a positive history of CVD (prevalent cases) at the baseline examination, had missing values for either CHD or smoking status, or participated in only 1 phase of the study were excluded (Figure 1).

\section{Exposure: cigarette smoking status}

Participants' cigarette smoking status was determined based on self-reported smoking behavior. Collected data on participants' history of current and previous smoking were used to categorize individuals as never, secondhand, former, former \& secondhand, and current smokers. Participants were considered to be ever smokers if they had smoked more than 100 cigarettes in their lifetime, while those who had not smoked cigarettes at all or had smoked 100 or fewer cigarettes in their lifetime and did not currently smoke were classified as never smokers. Ever smokers were assigned into 2 groups: participants who had smoked more than 100 cigarettes in their lifetime and had smoked in the last 28 days were considered to be current smokers, while ever smokers who had smoked more than 100 cigarettes in their lifetime but had quit smoking were considered as former smokers. Secondhand smokers (or those exposed to environmental tobacco smoke) were defined as never smokers who were exposed to cigarette smoke at home or at work. Former smokers who were exposed to others' cigarette smoke were defined as former \& secondhand smokers. Information was also gathered on age at initiation of cigarette smoking (categorized as $\leq 17$ years old and $>17$ years old), smoking intensity (number of cigarettes used per day), and history of smoking cessation (years).

\section{Outcome assessment}

All participants of the TLGS are followed up for any medical events during the preceding year by a telephone call, and are asked about any medical conditions by a trained nurse. In the present study, the outcome of interest was first CHD events. In order to gather outcome data, all participants were followed up annually for fatal or non-fatal CHD (definite MI, probable MI, unstable angina pectoris, angiography-proven $\mathrm{CHD}$ and unstable angina pectoris, angiography-proven $\mathrm{CHD}$, and $\mathrm{CHD}$ death, which are comparable to the categories in the International Classification of Diseases, 10th revision). CHD events leading to hospitalization or death were confirmed by an outcome committee (cohort outcome panel) consisting of the principal investigator, an internist, an endocrinologist, a cardiologist, an epidemiologist, and a physician (general practitioner) who collected outcome data [22,23].

\section{Covariates}

The potential covariates assessed in the present study were age, sex, body mass index (BMI), high-density lipoprotein (HDL) cholesterol (mg/dL), low-density lipoprotein (LDL) cholesterol $(\mathrm{mg} / \mathrm{dL})$, history of type 2 diabetes mellitus (T2DM), systolic 


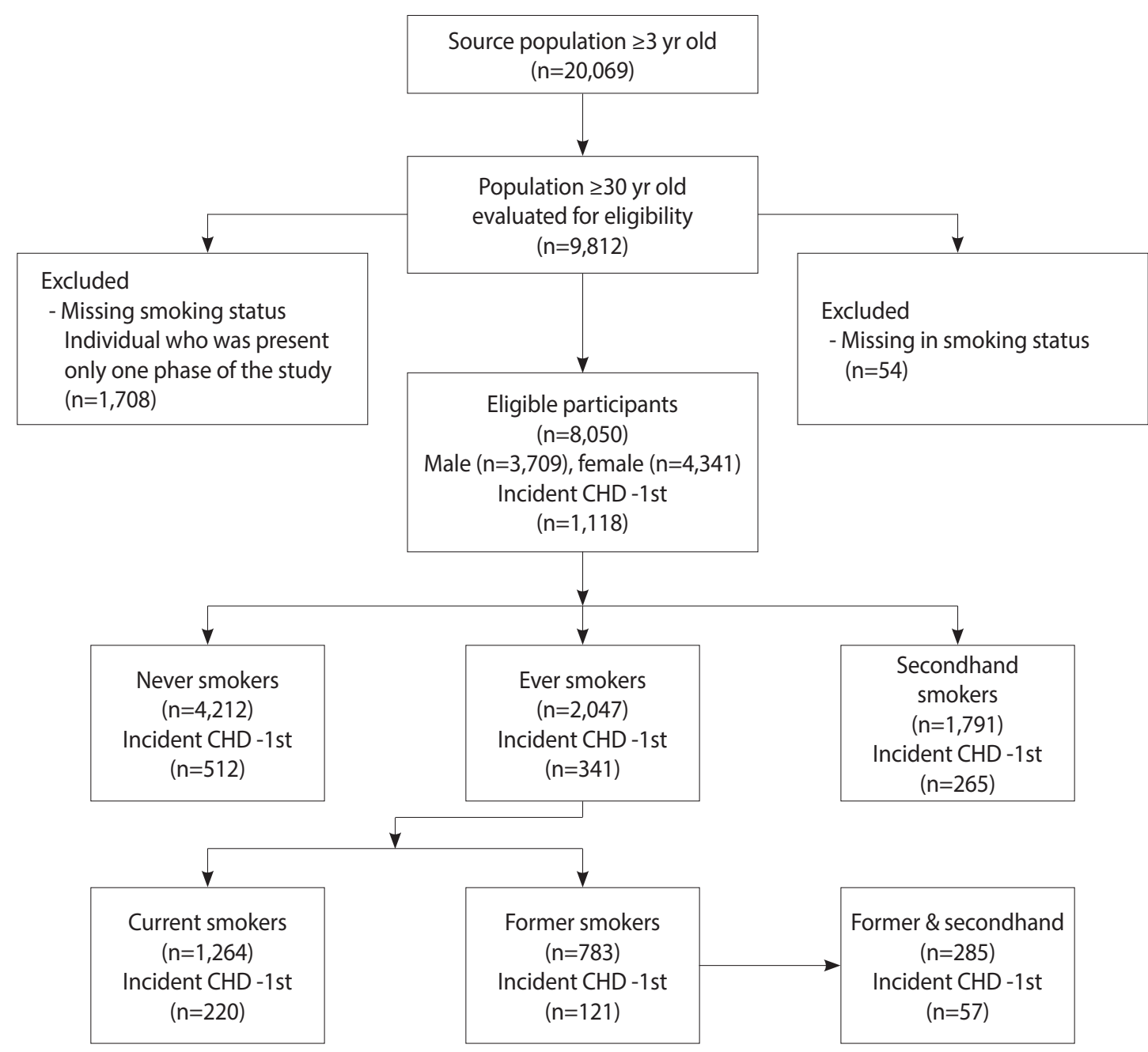

Figure 1. Flow diagram of study design and participants in the Tehran Lipid and Glucose Study cohort (1999-2018). CHD, coronary heart disease.

blood pressure (SBP, mmHg), diastolic blood pressure (DBP, $\mathrm{mmHg}$ ), and educational level (less than high school, high school and diploma, more than high school [college education]). Detailed information on anthropometric, clinical, and laboratory measurements have been described elsewhere [22,24].

\section{Statistical analysis}

A Cox proportional hazard regression model was used to estimate the hazard ratios (HRs) and 95\% confidence intervals (CIs) for CHD incidence after statistically and graphically assessing and confirming the proportional hazard assumption. A multivariable Cox model was used to estimate the HRs of CHD risk adjusted for age, sex, education level, and the aforementioned potential confounders stratified by smoking status (never, former, current, secondhand, and former \& secondhand). HRs were estimated in 4 models with increasing numbers of covariates, as follows: model 1 , smoking status alone; model 2, age as a covariate; model 3 , age and sex as covariates; and model 4 , model 3 plus education level,
BMI, history of T2DM, SBP, DBP, HDL cholesterol, and LDL cholesterol.

Since smoking intensity (cigarette/d) has been proposed as a preferable measure of smoking behavior for modeling cardiovascular outcomes [17], we estimated crude and fully adjusted HRs for CHD risk stratified by smoking intensity ( $\leq 10,10-20$, and $\geq 20$ cigarette/d). All statistical analyses were carried out using Stata version 14.0 (StataCorp., College Station, TX, USA) and SPSS 16.0 (SPSS Inc., Chicago, IL, USA). All statistical tests were 2 -tailed with significance level of $\alpha<0.05$. There were relatively few missing values (minimum for sex [0.2\%] and maximum for education level [5.1\%]) for all variables.

\section{Ethics statement}

The study was approved by the Shahid Beheshti University of Medical Sciences Ethics Committee (No. IR.SBMU.PHNS.REC. 1396.144). Written informed consent was obtained from all participants. 


\section{RESULTS}

The eligible participants for this study were 8,050 individuals aged 30 years or older. More of them were females (54.0\%) than males, with a mean age of $46.10 \pm 11.38$ years. During a median follow-up of 14.66 years, the participants experienced 1,118 first CHD events. First CHD events occurred more frequently in males than in females ( $8.2 \%$ vs. $5.6 \%)$. The majority $(61.0 \%)$ of the CHD cases occurred before the age of 65 years. Fewer than $15 \%$ of the study population had a history of T2DM and both sexes were, on average, overweight (mean BMI, $27.5 \pm 4.6 \mathrm{~kg} / \mathrm{m}^{2}$ ). One-quarter of the participants reported a history of cigarette smoking (25.4\%), of which 3.4\% were females. Among those who reported no history of cigarette smoking, $22.2 \%$ were exposed to secondhand smoke, with a higher proportion among females than among males. A considerable proportion of ever smokers $(36.2 \%)$ had initiated cigarette smoking in adolescence. The baseline participant characteristics are shown in Table 1.

The distribution of the first CHD events and all study covariates stratified by cigarette smoking status is presented in Table 2. Former smokers accounted for the highest proportion of CHD cases, followed by former \& secondhand, current, never, and secondhand smokers $(24.3 \%, 20.0 \%, 17.4 \%, 12.2 \%$, and $11.6 \%$, respectively). Only $9.4 \%$ of current smokers reported that they smoked $\geq 20$ cigarette/d, and approximately $70 \%$ of the former \& secondhand smokers had quit smoking more than 5 years ago.

In both the crude and multivariable-adjusted models, exposure to cigarette smoking-regardless of being active or passive-was associated with a significantly increased risk of CHD compared to never smoking (Table 3). Surprisingly, the association between

Table 1. Distribution of baseline characteristics of the cohort (TLGS; 1999-2018)

\begin{tabular}{|c|c|c|c|}
\hline Characteristics & Male $(n=3,709)$ & Female $(n=4,341)$ & Total $(n=8,050)$ \\
\hline Age (yr) & $47.76 \pm 12.82$ & $46.10 \pm 11.38$ & $46.89 \pm 12.11$ \\
\hline Incident CHD (first event) & $663(8.2)$ & $455(5.6)$ & $1,118(13.8)$ \\
\hline \multicolumn{4}{|l|}{ Education level (yr) } \\
\hline Did not graduate & $326(4.3)$ & $375(4.9)$ & $701(9.2)$ \\
\hline Less than high school $(\leq 9)$ & $1,378(18.1)$ & $2,100(27.5)$ & $3,478(45.6)$ \\
\hline High school (10-12) & $1,156(15.2)$ & $1,170(15.3)$ & $2,326(30.5)$ \\
\hline More than high school (>12) & $660(8.7)$ & $467(6.1)$ & $1,127(14.8)$ \\
\hline \multicolumn{4}{|l|}{ History of cigarette smoking } \\
\hline No history & $1,933(24.1)$ & $4,057(50.5)$ & $6,003(74.6)$ \\
\hline Positive history & $1,770(22.0)$ & $275(3.4)$ & $2,047(25.4)$ \\
\hline \multicolumn{4}{|l|}{ Smoking status } \\
\hline Never & $1,263(15.7)$ & 2,949 (36.6) & $4,212(52.3)$ \\
\hline Former & $674(8.4)$ & $109(1.4)$ & $783(9.7)$ \\
\hline Current & $1,096(13.6)$ & $168(2.1)$ & $1,264(15.7)$ \\
\hline Secondhand & $670(8.3)$ & $1,121(13.9)$ & $1,791(22.2)$ \\
\hline Age at smoking initiation (yr) & $20.65 \pm 10.23$ & $26.07 \pm 13.53$ & $21.50 \pm 10.98$ \\
\hline$\leq 17$ & $599(33.6)$ & $47(2.6)$ & 647 (36.2) \\
\hline$>17$ & $952(53.4)$ & $185(10.4)$ & $1,138(63.8)$ \\
\hline \multicolumn{4}{|c|}{ History of using non-cigarette forms of tobacco } \\
\hline No history & $2,699(33.8)$ & $3,987(49.7)$ & $6,700(83.5)$ \\
\hline Positive history & $983(12.3)$ & $336(4.2)$ & $1,320(16.5)$ \\
\hline \multicolumn{4}{|l|}{ History of type 2 diabetes } \\
\hline No diabetes & $2,376(26.5)$ & $2,622(36.7)$ & $4,229(63.2)$ \\
\hline Pre-diabetes & $830(9.2)$ & $974(13.6)$ & $1,804(22.8)$ \\
\hline Diabetes & $476(5.1)$ & $633(8.9)$ & $1,109(14.0)$ \\
\hline No. of cigarette per day (n) & $10[5-20]$ & $12[5-20]$ & $8[5-11]$ \\
\hline Smoking cessation (yr) & $11[5-20]$ & $11[4-20]$ & $13[5-22]$ \\
\hline $\mathrm{SBP}(\mathrm{mmHg})$ & $121.26 \pm 18.61$ & $121.05 \pm 20.29$ & $121.14 \pm 19.53$ \\
\hline $\mathrm{DBP}(\mathrm{mmHg})$ & $78.32 \pm 11.04$ & $78.65 \pm 10.91$ & $78.50 \pm 10.97$ \\
\hline LDL-C (mg/dL) & $132.05 \pm 36.17$ & $139.57 \pm 39.89$ & $136.08 \pm 38.40$ \\
\hline $\mathrm{HDL}-\mathrm{C}(\mathrm{mg} / \mathrm{dL})$ & $37.84 \pm 9.29$ & $44.60 \pm 11.16$ & $41.47 \pm 10.87$ \\
\hline Non-HDLC (mg/dL) & $173.11 \pm 41.92$ & $177.61 \pm 47.71$ & $175.65 \pm 45.35$ \\
\hline Body mass index $\left(\mathrm{kg} / \mathrm{m}^{2}\right)$ & $26.29 \pm 3.96$ & $28.53 \pm 4.79$ & $27.49 \pm 4.56$ \\
\hline
\end{tabular}

Values are presented as mean \pm standard deviation or number (\%) or median [range].

TGLS, Tehran Lipid and Glucose Study; CHD, coronary heart disease; SBP, systolic blood pressure; DBP, diastolic blood pressure; LDL-C, low-density lipoprotein cholesterol; HDL-C, high-density lipoprotein cholesterol. 
Sadeghi M et al. : Secondhand smoke exposure in former smokers and CHD risk

Table 2. Description of baseline cohort characteristics stratified by cigarette smoking status (TLGS; 1999-2018)

\begin{tabular}{|c|c|c|c|c|c|}
\hline \multirow[b]{2}{*}{ Characteristics } & \multicolumn{5}{|c|}{ Smoking status } \\
\hline & $\begin{array}{c}\text { Never } \\
(n=4,212)\end{array}$ & $\begin{array}{l}\text { Former } \\
(n=498)\end{array}$ & $\begin{array}{l}\text { Current } \\
(n=1,264)\end{array}$ & $\begin{array}{l}\text { Secondhand } \\
(n=1,791)\end{array}$ & $\begin{array}{l}\text { Former \& secondhanc } \\
\qquad(n=285)\end{array}$ \\
\hline Age (yr) & $47.49 \pm 12.37$ & $54.25 \pm 12.84$ & $44.85 \pm 10.76$ & $44.66 \pm 11.05$ & $48.32 \pm 12.77$ \\
\hline Coronary heart disease & $512(12.2)$ & $121(24.3)$ & $220(17.4)$ & $208(11.6)$ & $57(20.0)$ \\
\hline Sex/male & $1,263(30.1)$ & $420(84.3)$ & $1,096(86.8)$ & $670(37.5)$ & $254(89.1)$ \\
\hline \multicolumn{6}{|l|}{ Education level (yr) } \\
\hline Did not graduate & $354(8.8)$ & $50(10.5)$ & $109(9.1)$ & $164(9.8)$ & $26(9.5)$ \\
\hline Less than high school $(\leq 9)$ & $1,969(49.0)$ & $224(47.3)$ & $454(37.8)$ & $727(43.4)$ & $108(39.6)$ \\
\hline High school (10-12) & $1,146(28.5)$ & $121(25.5)$ & $454(37.8)$ & $513(30.6)$ & $95(34.8)$ \\
\hline More than high school (>12) & $549(13.7)$ & 79 (16.7) & $184(15.3)$ & $271(16.2)$ & $44(16.1)$ \\
\hline \multicolumn{6}{|l|}{ Age at starting smoking (yr) } \\
\hline$\leq 17$ & NA & $102(26.4)$ & $502(40.5)$ & NA & $47(27.3)$ \\
\hline$>17$ & NA & $276(73.5)$ & $737(59.5)$ & NA & $125(72.7)$ \\
\hline \multicolumn{6}{|l|}{ Intensity (cigarette/d) } \\
\hline$<10$ & NA & $77(88.5)$ & $576(46.5)$ & NA & $44(86.3)$ \\
\hline $10-19$ & NA & $9(10.3)$ & $548(44.2)$ & NA & $6(11.8)$ \\
\hline$\geq 20$ & NA & $1(1.1)$ & $116(9.4)$ & NA & $1(2.0)$ \\
\hline \multicolumn{6}{|l|}{ History of smoking cessation (yr) } \\
\hline$<5$ & NA & $105(21.4)$ & NA & NA & $83(29.6)$ \\
\hline $5-9$ & NA & 90 (18.4) & NA & NA & $52(18.6)$ \\
\hline $10-14$ & NA & $77(15.7)$ & NA & NA & $45(16.1)$ \\
\hline $15-24$ & NA & $129(26.3)$ & NA & NA & $55(19.6)$ \\
\hline$\geq 25$ & NA & $89(18.2)$ & NA & NA & $45(16.1)$ \\
\hline \multicolumn{6}{|l|}{ Body mass index $\left(\mathrm{kg} / \mathrm{m}^{2}\right)$} \\
\hline$<18.5$ & $31(0.7)$ & $4(0.8)$ & $40(3.2)$ & $12(0.7)$ & $5(1.8)$ \\
\hline $18.5-24.9$ & $1,056(25.2)$ & $157(31.6)$ & $491(39.0)$ & $455(25.5)$ & $92(32.3)$ \\
\hline $25-29.9$ & $1,844(43.9)$ & $230(46.3)$ & $533(42.3)$ & $792(44.4)$ & $133(46.7)$ \\
\hline$\geq 30.0$ & $1,267(30.2)$ & $106(21.3)$ & $196(15.6)$ & $524(29.4)$ & $55(19.3)$ \\
\hline \multicolumn{6}{|l|}{ History of type 2 diabetes } \\
\hline No diabetes & $2,514(61.4)$ & $258(53.3)$ & $877(71.8)$ & $1,145(66.5)$ & $169(61.0)$ \\
\hline Pre-diabetes & $987(24.1)$ & $134(27.7)$ & $118(9.7)$ & $222(12.7)$ & $47(17.0)$ \\
\hline Diabetes & $591(14.4)$ & $92(19.0)$ & $226(18.5)$ & $381(21.8)$ & $61(22.0)$ \\
\hline \multicolumn{6}{|l|}{ Blood pressure (mmHg) } \\
\hline SBP & $122.72 \pm 20.01$ & $126.20 \pm 20.20$ & $115.31 \pm 17.13$ & $119.87 \pm 18.97$ & $119.86 \pm 18.97$ \\
\hline DBP & $79.47 \pm 10.96$ & $79.22 \pm 10.99$ & $74.94 \pm 10.38$ & $78.51 \pm 10.63$ & $78.51 \pm 10.63$ \\
\hline LDL-C (mg/dL) & $43.09 \pm 10.92$ & $39.43 \pm 9.56$ & $37.37 \pm 9.69$ & $41.63 \pm 11.17$ & $132.66 \pm 36.18$ \\
\hline $\mathrm{HDL}-\mathrm{C}(\mathrm{mg} / \mathrm{dL})$ & $138.81 \pm 39.59$ & $140.28 \pm 37.99$ & $131.07 \pm 36.31$ & $132.66 \pm 36.18$ & $41.63 \pm 11.17$ \\
\hline
\end{tabular}

Values are presented as mean \pm standard deviation or number (\%).

TGLS, Tehran Lipid and Glucose Study; SBP, systolic blood pressure; DBP, diastolic blood pressure; LDL-C, low-density lipoprotein cholesterol; HDL-C, high-density lipoprotein cholesterol; NA, not applicable.

cigarette smoking and CHD was stronger in former smokers (HR, 2.26; $95 \% \mathrm{CI}, 1.85$ to 2.75 ) than in current smokers (HR, 1.58; $95 \%$ CI, 1.35 to 1.86 ) in the crude model (Table 3 and Figure $2 \mathrm{~A}$ ). A remarkable finding of the present study was the important and significant risk of CHD in former \& secondhand smokers (HR, 1.86 ; $95 \%$ CI, 1.41 to 2.44 ). After adjusting for age as the main covariate, the associations in former smokers and current smokers changed meaningfully; the risk of CHD increased in current smokers (HR, 2.07; 95\% CI, 1.76 to 2.43), but decreased in former smokers (HR, 1.56 ; $95 \% \mathrm{CI}, 1.28$ to 1.91$)$.
It is interesting to note that in former \& secondhand smokers, the considerable observed association remained almost unchanged upon adjustment (HR, 1.82; 95\% CI, 1.38 to 2.39 ). In other words, in individuals who were still exposed to others' cigarette smoke despite quitting smoking, the risk of $\mathrm{CHD}$ was 1.8 times more than in never smokers. After controlling for age, sex, education level, BMI, history of T2DM, SBP, DBP, HDL cholesterol, and LDL cholesterol, the risk of CHD was highest in current smokers, followed in order by former \& secondhand smokers, former smokers, and secondhand smokers (HR, 1.99; 95\% CI, 1.65 to 2.39 ; HR, 1.55; 95\% CI, 
Table 3. Multivariable-adjusted risk of CHD stratified by cigarette smoking status (TLGS; 1999-2018)

\begin{tabular}{|c|c|c|c|c|c|c|}
\hline Variables & $\begin{array}{l}\text { No. of people } \\
\text { (n) }\end{array}$ & $\begin{array}{l}\text { No. of CHD } \\
\text { events (n) }\end{array}$ & Model 1 & Model 2 & Model 3 & Model 4 \\
\hline \multicolumn{7}{|l|}{ Smoking status } \\
\hline Never & 4,212 & 512 & 1.00 (reference) & 1.00 (reference) & 1.00 (reference) & 1.00 (reference) \\
\hline Former & 498 & 121 & $2.26(1.85,2.75)$ & $1.56(1.28,1.91)$ & $1.37(1.11,1.69)$ & $1.39(1.12,1.72)$ \\
\hline Current & 1,264 & 220 & $1.58(1.35,1.86)$ & $2.07(1.76,2.43)$ & $1.76(1.48,2.09)$ & $1.99(1.65,2.39)$ \\
\hline Secondhand & 1,791 & 208 & $1.02(0.87,1.20)$ & $1.27(1.07,1.49)$ & $1.24(1.05,1.46)$ & $1.27(1.07,1.51)$ \\
\hline Former \& secondhand & 285 & 57 & $1.86(1.41,2.44)$ & $1.82(1.38,2.39)$ & $1.58(1.19,2.09)$ & $1.55(1.15,2.08)$ \\
\hline Age, mean (yr) & - & - & - & $1.07(1.06,1.07)$ & $1.06(1.06,1.07)$ & $1.05(1.05,1.06)$ \\
\hline \multicolumn{7}{|l|}{ Sex } \\
\hline Female & 4,341 & 455 & - & - & 1.00 (reference) & 1.00 (reference) \\
\hline Male & 3,709 & 663 & - & - & $1.37(1.19,1.57)$ & $1.57(1.35,1.84)$ \\
\hline \multicolumn{7}{|l|}{ Education (yr) } \\
\hline Did not graduate & 326 & 113 & - & - & - & 1.00 (reference) \\
\hline$\leq 9$ & 1,378 & 547 & - & - & - & $0.92(0.76,1.15)$ \\
\hline $10-12$ & 1,156 & 262 & & & & $0.88(0.70,1.11)$ \\
\hline$>12$ & 655 & 134 & - & - & - & $0.78(0.59,1.01)$ \\
\hline \multicolumn{7}{|l|}{ T2DM } \\
\hline No diabetes & 2,376 & 468 & - & - & - & 1.00 (reference) \\
\hline Pre-diabetes & 830 & 292 & - & - & - & $1.21(1.04,1.42)$ \\
\hline Diabetes & 476 & 327 & - & - & - & $1.91(1.99,2.72)$ \\
\hline BMI $\left(\mathrm{kg} / \mathrm{m}^{2}\right)$ & - & - & - & - & - & $1.01(0.99,1.01)$ \\
\hline $\mathrm{SBP}(\mathrm{mmHg})$ & - & - & - & - & - & $1.01(1.00,1.01)$ \\
\hline $\mathrm{DBP}(\mathrm{mmHg})$ & - & - & - & - & - & $1.01(1.00,1.01)$ \\
\hline LDL-C (mg/dL) & - & - & - & - & - & $1.01(1.00,1.01)$ \\
\hline HDL-C (mg/dL) & - & - & - & - & - & $0.98(0.98,0.99)$ \\
\hline
\end{tabular}

Values are presented as hazard ratio (95\% confidence interval).

Model 1: crude model (smoking status alone); Model 2: adjusted for age; Model 3: adjusted for age and sex; Model 4: adjusted for age, sex, education level, T2DM, BMI, SBP, DBP, LDL-C, and HDL-C.

CHD, coronary heart disease; TGLS, Tehran Lipid and Glucose Study; T2DM, type 2 diabetes mellitus; BMl, body mass index; SBP, systolic blood pressure; DBP, diastolic blood pressure; LDL-C, low-density lipoprotein cholesterol; HDL-C, high-density lipoprotein cholesterol.

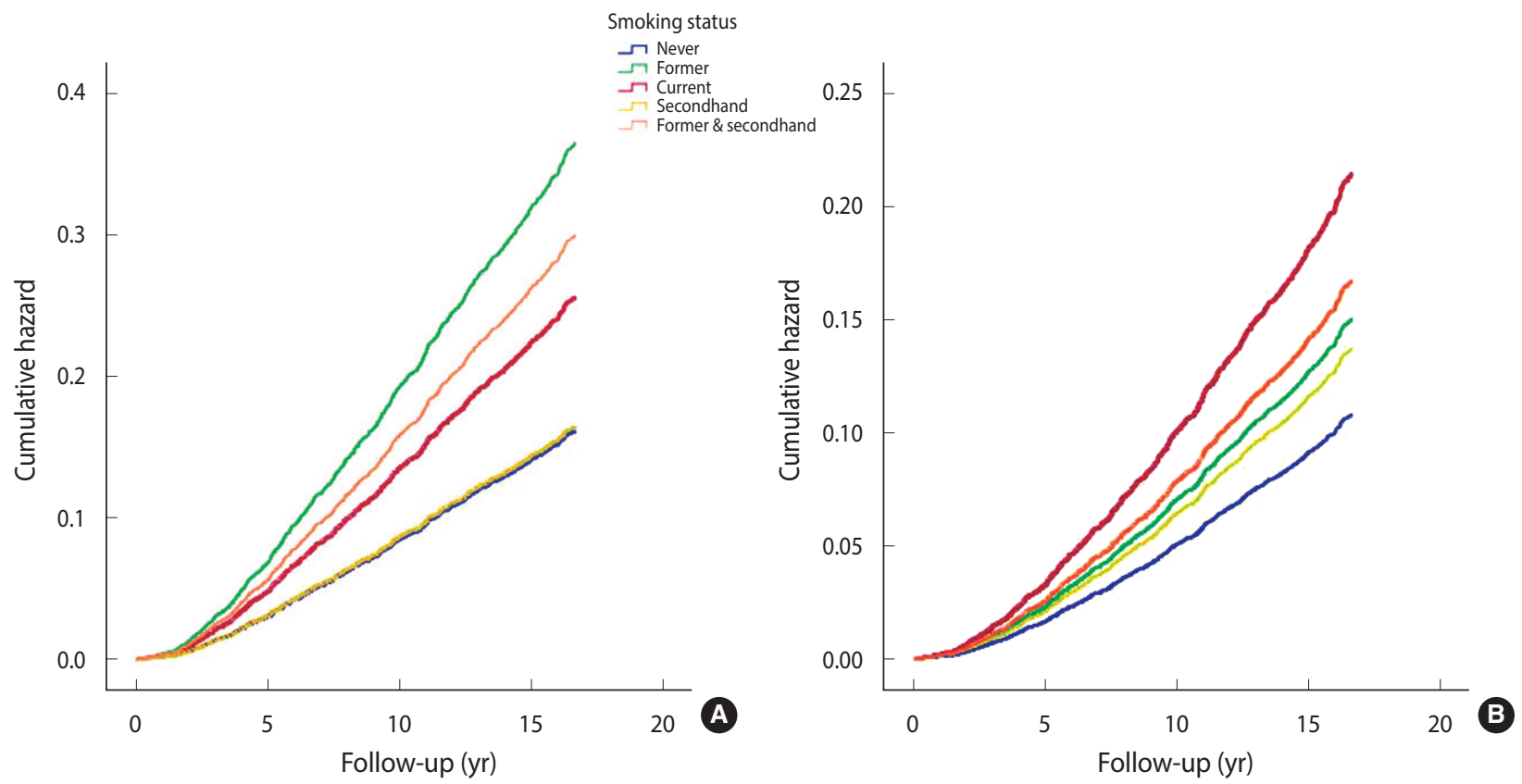

Figure 2. Risk of coronary heart disease based on crude (A) and multivariable fully adjusted model (B) by cigarette smoking status. 
Table 4. Multivariable-adjusted risk of CHD stratified by smoking intensity (TLGS; 1999-2018)

\begin{tabular}{|c|c|c|c|c|c|c|}
\hline Variables & $\begin{array}{c}\text { No. of } \\
\text { people (n) }\end{array}$ & $\begin{array}{l}\text { No. of CHD } \\
\text { events (n) }\end{array}$ & Model 1 & Model 2 & Model 3 & Model 4 \\
\hline \multicolumn{7}{|c|}{ Smoking intensity (cigarette/d) } \\
\hline Never smoker & 6,003 & 720 & 1.00 (reference) & 1.00 (reference) & 1.00 (reference) & 1.00 (reference) \\
\hline$<10$ & 830 & 124 & $1.36(1.11,1.66)$ & $1.71(1.40,2.10)$ & $1.52(1.23,1.89)$ & $1.65(1.32,2.06)$ \\
\hline $10-19$ & 455 & 96 & $1.76(1.43,2.15)$ & $2.18(1.78,2.68)$ & $1.87(1.50,2.33)$ & $2.22(1.75,2.80)$ \\
\hline$\geq 20$ & 88 & 24 & $2.31(1.58,2.37)$ & $2.74(1.87,3.99)$ & $2.31(1.56,3.41)$ & $2.38(1.58,3.58)$ \\
\hline Age, mean (yr) & - & - & & $1.07(1.06,1.07)$ & $1.07(1.06,1.07)$ & $1.06(1.05,1.06)$ \\
\hline \multicolumn{7}{|l|}{ Sex } \\
\hline Female & 4,341 & 455 & - & - & 1.00 (reference) & 1.00 (reference) \\
\hline Male & 3,709 & 663 & - & - & $1.32(1.14,1.52)$ & $1.46(1.24,1.72)$ \\
\hline \multicolumn{7}{|l|}{ Education (yr) } \\
\hline Did not graduate & 326 & 113 & - & - & - & 1.00 (reference) \\
\hline$\leq 9$ & 1,378 & 547 & - & - & - & $0.88(0.70,1.11)$ \\
\hline $10-12$ & 1,156 & 262 & & & & $0.86(0.67,1.10)$ \\
\hline$>12$ & 655 & 134 & - & - & - & $0.75(0.56,0.99)$ \\
\hline \multicolumn{7}{|l|}{ T2DM } \\
\hline No diabetes & 2,376 & 468 & - & - & - & 1.00 (reference) \\
\hline Pre-diabetes & 830 & 292 & - & - & - & $1.25(1.06,1.47)$ \\
\hline Diabetes & 476 & 327 & - & - & - & $2.48(2.10,2.94)$ \\
\hline BMI $\left(\mathrm{kg} / \mathrm{m}^{2}\right)$ & - & - & - & - & - & $1.02(1.00,1.03)$ \\
\hline $\mathrm{SBP}(\mathrm{mmHg})$ & - & - & - & - & - & $1.01(1.00,1.01)$ \\
\hline $\mathrm{DBP}(\mathrm{mmHg})$ & - & - & - & - & - & $1.02(1.00,1.02)$ \\
\hline LDL cholesterol (mg/dL) & - & - & - & - & - & $1.01(1.00,1.01)$ \\
\hline HDL cholesterol (mg/dL) & - & - & - & - & - & $0.98(0.97,0.99)$ \\
\hline
\end{tabular}

Values are presented as hazard ratio (95\% confidence interval).

Model 1: crude model (smoking status alone); Model 2: adjusted for age; Model 3: adjusted for age and sex; Model 4: adjusted for age, sex, education level, T2DM, BMI, SBP, DBP, LDL cholesterol, and HDL cholesterol.

CHD, coronary heart disease; TGLS, Tehran Lipid and Glucose Study; T2DM, type 2 diabetes mellitus; BMI, body mass index; SBP, systolic blood pressure; DBP, diastolic blood pressure; LDL-C, low-density lipoprotein cholesterol; HDL-C, high-density lipoprotein cholesterol.

1.15 to 2.08 ; HR, $1.39,95 \%$ CI, 1.12 to 1.72 ; HR, 1.27 ; $95 \%$ CI, 1.07 to 1.51 ), compared to never smokers (Table 3, Figure 2B).

As illustrated in the fully adjusted model shown in Table 3, the risk of CHD in males was 1.57 times higher than in females (HR, 1.57; 95\% CI, 1.35 to 1.84 ). Although education level did not have a significant effect on CHD incidence, it did seem that more than 12 years of formal education (more than high school) had a statistically borderline protective effect against CHD, reducing its incidence by nearly $20 \%$ (HR, $0.78 ; 95 \%$ CI, 0.59 to 1.01).

When smoking status (the study exposure) was replaced with smoking intensity as another measure of cigarette smoking, evidence of a significant dose-response pattern between a higher number of cigarettes per day and risk of CHD was observed. To summarize, in both the crude and fully adjusted models, the risk of CHD increased with greater smoking intensity ( $<10$ cigarette/ d: HR, 1.65; 95\% CI, 1.32 to 2.06; 10-19 cigarette/d: HR, 2.22; 95\% CI, 1.75 to 2.80 ; and $\geq 20$ cigarette/d: HR, 2.38 ; $95 \% \mathrm{CI}, 1.58$ to 3.58) (Table 4).

\section{DISCUSSION}

In this large population-based prospective cohort from Iran with a remarkable median length of follow-up, the risk for incident CHD was higher in current, former \& secondhand, former, and secondhand smokers (with fully adjusted HRs of 1.99, 1.55, 1.39 , and 1.27 , respectively) than in never smokers, independently of other CHD risk factors. It is worth emphasizing that the risk of CHD events in participants who had quit smoking but were exposed to others' cigarette smoke at home or work was 1.55 times higher than that of never smokers, while the risk was 1.39 times higher in those with a history of cigarette smoking (former smokers) and 1.27 times in never smokers who were exposed to others' cigarette smoke (secondhand smokers). In another study that dealt with the influence of smoking intensity (cigarette/d) on incidence of $\mathrm{CHD}$, a considerable risk of $\mathrm{CHD}$ was found to be associated with even light cigarette smoking (1-10 cigarette/d). CHD events occurred $65 \%$ more frequently in light smokers than in those with no history of cigarette smoking. This window of hazard for incident CHD was greater for those who smoked more 
than 10 cigarette/d (more than twice than never smokers). This is a key message for smokers who suppose that light smoking is less risky or harmless.

Our results are consistent with previously conducted large cohort studies from various nations [17,18,25-30] and offer more evidence to support the association between smoking and risk of CHD. In the Framingham heart cohort study, which contained 8,770 participants with a mean age of $42.2 \pm 11.8$ years, the risk of CVD was meaningfully higher (75\%) in current smokers than in never smokers, whereas former smokers-regardless of intensity-were not at an increased risk [18], suggesting that risk may drop as time passes after quitting smoking. The relative risk of CVD events for never smokers exposed to secondhand smoke (secondhand smokers) in comparison with those unexposed (never smokers) was 1.23 (95\% CI, 1.16 to 1.31 ) in a systematic review conducted of 38 large observational studies [31]. Of note, however, the observed association between secondhand smoke exposure and CVD was distinctly stronger among Chinese than among Americans [31].

It is widely supposed that quitting smoking is associated with a significant reduction in the risk of death among patients with CHD. Irrespective of age, sex, index cardiac event, country, and the year of study initiation, this mortality risk reduction seems to be consistent [32].

It is even believed that the risk of sudden cardiac death in smokers who have quit smoking more than 20 years ago is equivalent to that of never smokers [33]. However, those with a history of cigarette smoking are less sensitive to others' cigarette smoke (secondhand smoke). Studies conducted on environmental tobacco smoke/secondhand smoke suggest that its effects on the risk of CHD are stronger than would be expected based on associations in current smokers who are exposed to higher doses of cigarette smoke [34]. There are some who argue that current smokers may have adaptive responses that lead to lower increases in $\mathrm{CHD}$ risk at high levels of exposure compared to the increases in risks experienced by light secondhand smokers $[35,36]$. The available evidence suggests that cardiovascular system, platelet, and endothelial function [37-39]; atherosclerosis and arterial stiffness $[40,41]$; oxidative stress [42]; inflammation [43,44]; and infarct size are highly sensitive to the toxins in secondhand smoke. The effects of even short-term exposure (minutes to hours) to secondhand smoke are nearly as large (on average $80-90 \%$ ) as current smoking [45].

The current analysis confirmed the findings discussed above and provided further evidence for the association between secondhand smoke exposure and the risk of CHD events. In addition, a notable finding of our study was that the risk of CHD in former smokers who were exposed to others' cigarette smoke (former \& secondhand smokers) was higher than in secondhand smokers and former smokers, respectively, and approached that of current smokers. However this group-as a separate category of smoking status-has not been examined in other studies. Since this is an important issue, further research should be done to con- firm this finding.

Regarding smoking intensity, our findings also confirmed the results of research conducted in recent years [17,27-29,46,47]. The average baseline smoking intensity (cigarette/d) was significantly associated with incidence of CHD in a dose-response pattern. Slight inconsistencies in the magnitude of the risk among studies may be attributed to diversity in study participants, or may be due to residual confounding and/or interaction with other baseline factors including physical activity, nutritional factors, and genetic factors [48].

Strengths of the present study include the analysis of a large population-based prospective cohort with a considerable sample size and more than 14 years of follow-up. The tracking and frequent follow-up of participants, as well as the in-person assessment of their smoking histories, resulted in a comprehensive picture of exposure. Because a comprehensive range of potential covariates related to $\mathrm{CHD}$ was considered, the estimated HRs can be considered valid and accurate. Modeling of smoking history in the context of CHD was performed using 2 distinct measures of cigarette smoking (smoking status and smoking intensity).

Nonetheless, there are several sources of uncertainty in the present study. Although information on participants' smoking histories was obtained in person, the recorded data on duration of smoking cessation and history of other types of tobacco consumption were not very reliable. Furthermore, recall bias may have influenced the self-reported data on smoking initiation and the exact date of quitting smoking. Our analysis might have underestimated the true HRs because of the social stigma towards cigarette smoking among Iranian females, which may have led to underreporting of cigarette smoking by female participants. Finally, the possibility of residual confounding in our model should be considered, despite careful adjustment for the main confounders.

The findings of this large population-based prospective cohort study indicate that current, former \& secondhand, former, and secondhand smokers had an elevated risk of incident CHD (in descending order) compared to never smokers. Furthermore, evidence of a significant dose-response pattern between the number of cigarettes smoked per day (smoking intensity) and the risk of $\mathrm{CHD}$ was observed. The finding of a considerably elevated risk of CHD in individuals who were exposed to others' cigarette smoke after smoking cessation is remarkable. This study has raised this important issue, which needs further exploration. Efforts should be made to convey this message to health policy-makers and government officials to improve effective tobacco control and anti-smoking strategies, especially in communities where the prevalence of smoking is increasing, but laws making public environments smoke-free have not been passed due to a lack of political commitment, provided that our findings are confirmed by future studies.

\section{CONFLICT OF INTEREST}

The authors have no conflicts of interest to declare for this study. 


\section{FUNDING}

None.

\section{ACKNOWLEDGEMENTS}

The authors would like to thank all participants of this study for their cooperation.

\section{AUTHOR CONTRIBUTIONS}

Conceptualization: HS, MS, Data curation: MSD, MA. Formal analysis: MS, SK. Funding acquisition: None. Methodology: HS, MS, SK, AAM. Project administration: HS. Writing - original draft: MS, HS, AAM, SK, MSD, MA. Writing - review \& editing: HS, MS.

\section{ORCID}

Masoumeh Sadeghi: http://orcid.org/0000-0001-9648-4684; Maryam S. Daneshpour: http://orcid.org/0000-0003-1525-8672; Soheila Khodakarim: http://orcid.org/0000-0002-5473-999X; Amir Abbas Momenan: http://orcid.org/0000-0001-7339-0693; Mahdi Akbarzadeh: http://orcid.org/0000-0002-8048-744X; Hamid Soori: http://orcid.org/0000-0002-3775-1831

\section{REFERENCES}

1. GBD 2017 Causes of Death Collaborators. Global, regional, and national age-sex-specific mortality for 282 causes of death in 195 countries and territories, 1980-2017: a systematic analysis for the Global Burden of Disease Study 2017. Lancet 2018;392:1736-1788.

2. Gaziano TA, Prabhakaran D, Gaziano JM. Global burden of cardiovascular disease. In: Mann DL, Zipes DP, Libby P, Bonow RO, Braunwald E, editors. Braunwald's heart disease: a textbook of cardiovascular medicine. 10th ed. Philadelphia: Saunders; 2015, p. 1-20.

3. Heidenreich PA, Trogdon JG, Khavjou OA, Butler J, Dracup K, Ezekowitz MD, et al. Forecasting the future of cardiovascular disease in the United States: a policy statement from the American Heart Association. Circulation 2011;123:933-944.

4. United Nations. Sustainable development knowledge platform [cited 2017 Apr 30]. Available from: https://sustainabledevelopment.un.org/.

5. Forouzanfar MH, Sepanlou SG, Shahraz S, Dicker D, Naghavi P, Pourmalek F, et al. Evaluating causes of death and morbidity in Iran, global burden of diseases, injuries, and risk factors study 2010. Arch Iran Med 2014;17:304-320.

6. Sadeghi M, Haghdoost AA, Bahrampour A, Dehghani M. Modeling the burden of cardiovascular diseases in Iran from 2005 to 2025: the impact of demographic changes. Iran J Public Health 2017;46:506-516.

7. World Health Organization. WHO report on the global tobacco epidemic 2019 [cited 2020 Mar 20]. Available from: https://www. who.int/tobacco/global_report/en/.

8. Ng M, Freeman MK, Fleming TD, Robinson M, Dwyer-Lindgren L, Thomson B, et al. Smoking prevalence and cigarette consumption in 187 countries, 1980-2012. JAMA 2014;311:183-192.

9. Hackshaw A, Morris JK, Boniface S, Tang JL, Milenković D. Low cigarette consumption and risk of coronary heart disease and stroke: meta-analysis of 141 cohort studies in 55 study reports. BMJ 2018;360:j5855.

10. Jha P, Ramasundarahettige C, Landsman V, Rostron B, Thun M, Anderson RN, et al. 21st-century hazards of smoking and benefits of cessation in the United States. N Engl J Med 2013;368:341-350.

11. Office on Smoking and Health. The health consequences of involuntary exposure to tobacco smoke: a report of the Surgeon General. Atlanta: Centers for Disease Control and Prevention; 2006, p. 509.

12. Benjamin EJ, Blaha MJ, Chiuve SE, Cushman M, Das SR, Deo R, et al. Heart disease and stroke statistics-2017 update: a report from the American Heart Association. Circulation 2017;135:e146-e603.

13. Nakamura K, Nakagawa H, Sakurai M, Murakami Y, Irie F, Fujiyoshi A, et al. Influence of smoking combined with another risk factor on the risk of mortality from coronary heart disease and stroke: pooled analysis of 10 Japanese cohort studies. Cerebrovasc Dis 2012;33:480-491.

14. Huxley RR, Woodward M. Cigarette smoking as a risk factor for coronary heart disease in women compared with men: a systematic review and meta-analysis of prospective cohort studies. Lancet 2011;378:1297-1305.

15. Oza S, Thun MJ, Henley SJ, Lopez AD, Ezzati M. How many deaths are attributable to smoking in the United States? Comparison of methods for estimating smoking-attributable mortality when smoking prevalence changes. Prev Med 2011;52:428-433.

16. Mons U, Müezzinler A, Gellert C, Schöttker B, Abnet CC, Bobak $\mathrm{M}$, et al. Impact of smoking and smoking cessation on cardiovascular events and mortality among older adults: meta-analysis of individual participant data from prospective cohort studies of the CHANCES consortium. BMJ 2015;350:h1551.

17. Nance R, Delaney J, McEvoy JW, Blaha MJ, Burke GL, Navas-Acien A, et al. Smoking intensity (pack/day) is a better measure than pack-years or smoking status for modeling cardiovascular disease outcomes. J Clin Epidemiol 2017;81:111-119.

18. Duncan MS, Freiberg MS, Greevy RA Jr, Kundu S, Vasan RS, Tindle HA, et al. Association of smoking cessation with subsequent risk of cardiovascular disease. JAMA 2019;322:642-650.

19. Azizi F, Madjid M, Rahmani M, Emami H, Mirmiran PA, Hadjipour R. Tehran Lipid and Glucose Study (TLGS): rationale and design. Iran J Endocrinol Metab 2000;2:77-86 (Persian).

20. Azizi F, Rahmani M, Emami H, Mirmiran PA, Hajipour R, Madjid M, et al. Cardiovascular risk factors in an Iranian urban population: Tehran Lipid and Glucose Study (phase 1). Soz Praventivmed 2002;47:408-426.

21. Khalili D, Azizi F, Asgari S, Zadeh-Vakili A, Momenan AA, Ghanbarian A, et al. Outcomes of a longitudinal population-based co- 
hort study and pragmatic community trial: findings from 20 years of the Tehran Lipid and Glucose Study. Int J Endocrinol Metab 2018;16(4 Suppl):e84748.

22. Azizi F, Ghanbarian A, Momenan AA, Hadaegh F, Mirmiran P, Hedayati $M$, et al. Prevention of non-communicable disease in a population in nutrition transition: Tehran Lipid and Glucose Study phase II. Trials 2009;10:5.

23. Khalili D, Sheikholeslami FH, Bakhtiyari M, Azizi F, Momenan AA, Hadaegh F. The incidence of coronary heart disease and the population attributable fraction of its risk factors in Tehran: a 10year population-based cohort study. PLoS One 2014;9:e105804.

24. Mirmiran P, Sherafat-Kazemzadeh R, Farahani SJ, Asghari G, Niroomand M, Momenan A, et al. Performance of different definitions of metabolic syndrome for children and adolescents in a 6-year follow-up: Tehran Lipid and Glucose Study (TLGS). Diabetes Res Clin Pract 2010;89:327-333.

25. Myint PK, Sinha S, Luben RN, Bingham SA, Wareham NJ, Khaw KT. Risk factors for first-ever stroke in the EPIC-Norfolk prospective population-based study. Eur J Cardiovasc Prev Rehabil 2008; 15:663-669.

26. Zhang QL, Baumert J, Ladwig KH, Wichmann HE, Meisinger C, Döring A. Association of daily tar and nicotine intake with incident myocardial infarction: results from the population-based MONICA/KORA Augsburg Cohort Study 1984-2002. BMC Public Health 2011;11:273.

27. Huxley RR, Yatsuya H, Lutsey PL, Woodward M, Alonso A, Folsom AR. Impact of age at smoking initiation, dosage, and time since quitting on cardiovascular disease in african americans and whites: the atherosclerosis risk in communities study. Am J Epidemiol 2012;175:816-826.

28. Hackshaw A, Morris JK, Boniface S, Tang JL, Milenković D. Low cigarette consumption and risk of coronary heart disease and stroke: meta-analysis of 141 cohort studies in 55 study reports. BMJ 2018;360:j5855.

29. Gellert C, Schöttker B, Müller H, Holleczek B, Brenner H. Impact of smoking and quitting on cardiovascular outcomes and risk advancement periods among older adults. Eur J Epidemiol 2013; 28:649-658.

30. Tindle HA, Stevenson Duncan M, Greevy RA, Vasan RS, Kundu S, Massion PP, et al. Lifetime smoking history and risk of lung cancer: results from the Framingham Heart Study. J Natl Cancer Inst 2018;110:1201-1207.

31. Lv X, Sun J, Bi Y, Xu M, Lu J, Zhao L, et al. Risk of all-cause mortality and cardiovascular disease associated with secondhand smoke exposure: a systematic review and meta-analysis. Int J Cardiol 2015;199:106-115.

32. Critchley JA, Capewell S. Mortality risk reduction associated with smoking cessation in patients with coronary heart disease: a systematic review. JAMA 2003;290:86-97.

33. Sandhu RK, Jimenez MC, Chiuve SE, Fitzgerald KC, Kenfield
SA, Tedrow UB, et al. Smoking, smoking cessation, and risk of sudden cardiac death in women. Circ Arrhythm Electrophysiol 2012;5:1091-1097.

34. Cox LA Jr. Low-dose nonlinear effects of smoking on coronary heart disease risk. Dose Response 2012;10:219-232.

35. Law MR, Morris JK, Wald NJ. Environmental tobacco smoke exposure and ischaemic heart disease: an evaluation of the evidence. BMJ 1997;315:973-980.

36. Law MR, Wald NJ. Environmental tobacco smoke and ischemic heart disease. Prog Cardiovasc Dis 2003;46:31-38.

37. Ambrose JA, Barua RS. The pathophysiology of cigarette smoking and cardiovascular disease: an update. J Am Coll Cardiol 2004; 43:1731-1737.

38. Rahman MM, Laher I. Structural and functional alteration of blood vessels caused by cigarette smoking: an overview of molecular mechanisms. Curr Vasc Pharmacol 2007;5:276-292.

39. Armani C, Landini L Jr, Leone A. Molecular and biochemical changes of the cardiovascular system due to smoking exposure. Curr Pharm Des 2009;15:1038-1053.

40. Yamaguchi Y, Matsuno S, Kagota S, Haginaka J, Kunitomo M. Peroxynitrite-mediated oxidative modification of low-density lipoprotein by aqueous extracts of cigarette smoke and the preventive effect of fluvastatin. Atherosclerosis 2004;172:259-265.

41. Yamaguchi Y, Haginaka J, Morimoto S, Fujioka Y, Kunitomo M. Facilitated nitration and oxidation of LDL in cigarette smokers. Eur J Clin Invest 2005;35:186-193.

42. Yamaguchi Y, Matsuno S, Kagota S, Haginaka J, Kunitomo M. Oxidants in cigarette smoke extract modify low-density lipoprotein in the plasma and facilitate atherogenesis in the aorta of Watanabe heritable hyperlipidemic rabbits. Atherosclerosis 2001; 156:109-117.

43. Bermudez EA, Rifai N, Buring JE, Manson JE, Ridker PM. Relation between markers of systemic vascular inflammation and smoking in women. Am J Cardiol 2002;89:1117-1119.

44. Zhang J, Liu Y, Shi J, Larson DF, Watson RR. Side-stream cigarette smoke induces dose-response in systemic inflammatory cytokine production and oxidative stress. Exp Biol Med (Maywood) 2002;227:823-829.

45. Barnoya J, Glantz SA. Cardiovascular effects of secondhand smoke: nearly as large as smoking. Circulation 2005;111:2684-2698.

46. Kenfield SA, Stampfer MJ, Rosner BA, Colditz GA. Smoking and smoking cessation in relation to mortality in women. JAMA 2008; 299:2037-2047.

47. Pope CA 3rd, Burnett RT, Krewski D, Jerrett M, Shi Y, Calle EE, et al. Cardiovascular mortality and exposure to airborne fine particulate matter and cigarette smoke: shape of the exposure-response relationship. Circulation 2009;120:941-948.

48. Gellert C, Schöttker B, Brenner H. Smoking and all-cause mortality in older people: systematic review and meta-analysis. Arch Intern Med 2012;172:837-844. 